\title{
Multirule Based Diagnostic Approach for the Fog Predictions Using WRF Modelling Tool
}

\author{
Swagata Payra ${ }^{1,2}$ and Manju Mohan ${ }^{1}$ \\ ${ }^{1}$ Centre for Atmospheric Sciences, Indian Institute of Technology Delhi, Hauz Khas, New Delhi 110016, India \\ ${ }^{2}$ Centre of Excellence in Climatology, BIT Mesra, Extension Centre Jaipur, 27 MIA, Jaipur, Rajasthan 302 017, India \\ Correspondence should be addressed to Manju Mohan; mmohan66@gmail.com
}

Received 5 March 2014; Revised 6 July 2014; Accepted 7 August 2014; Published 21 September 2014

Academic Editor: A. N. V. Satyanarayana

Copyright (c) 2014 S. Payra and M. Mohan. This is an open access article distributed under the Creative Commons Attribution License, which permits unrestricted use, distribution, and reproduction in any medium, provided the original work is properly cited.

\begin{abstract}
The prediction of fog onset remains difficult despite the progress in numerical weather prediction. It is a complex process and requires adequate representation of the local perturbations in weather prediction models. It mainly depends upon microphysical and mesoscale processes that act within the boundary layer. This study utilizes a multirule based diagnostic (MRD) approach using postprocessing of the model simulations for fog predictions. The empiricism involved in this approach is mainly to bridge the gap between mesoscale and microscale variables, which are related to mechanism of the fog formation. Fog occurrence is a common phenomenon during winter season over Delhi, India, with the passage of the western disturbances across northwestern part of the country accompanied with significant amount of moisture. This study implements the above cited approach for the prediction of occurrences of fog and its onset time over Delhi. For this purpose, a high resolution weather research and forecasting (WRF) model is used for fog simulations. The study involves depiction of model validation and postprocessing of the model simulations for MRD approach and its subsequent application to fog predictions. Through this approach model identified foggy and nonfoggy days successfully $94 \%$ of the time. Further, the onset of fog events is well captured within an accuracy of 30-90 minutes. This study demonstrates that the multirule based postprocessing approach is a useful and highly promising tool in improving the fog predictions.
\end{abstract}

\section{Introduction}

Fog forecasting is extremely important as it not only causes low visibility but also is considered as a hazard as it disrupts the normal life and traffic. The prediction of fog onset however remains difficult despite the progress in numerical weather prediction. Few studies have attempted to describe the fog environment in terms of appropriate boundary layer temperature, humidity, wind speed, and wind direction, as well as near-surface radiative cooling profiles, advection currents, and characteristics of the underlying surface [1-6].

Numerical modeling of fog is improving day by day. Many scientists focus on the application of one-dimensional models for fog simulations; despite ignoring horizontal heterogeneities, it provides insights into fog physics [7]. But one dimensional model cannot explicitly incorporate large scale meteorological conditions that control the genesis, evolution, and dissipation of fog. So, in particular, only a three-dimensional model can incorporate, explicitly and in a dynamically consistent way, processes like (horizontal) pressure gradient, advection, and diffusion. The first such fog prediction with a regional 3-D model has been attempted by Ballard et al. [8]. Since then many further similar models have been attempted for fog prediction [9-14]. Still, there are only few specific studies [15-18], over India, for fog simulation and prediction. Delhi, the capital of India, is characterized by a high frequency of fog events and this generates many tragic traffic accidents and problems at the airports. Fog most frequently occurs during peak winter from December to January months over this region. An analysis of visibility data of Delhi for winter season clearly shows a very small percentage (6.4\%) of fog frequency during 1950-1955 (prior to urbanization) in comparison to 1996 to 2001 when it is $58 \%$ [19] whereas years 2002 to 2011 show that fog occurrences 
TABLE 1: Number of occurrences of fog days over Delhi in winter months (January, February, November, and December) of 2002 to 2011.

\begin{tabular}{|c|c|c|c|c|c|c|c|c|}
\hline \multirow{2}{*}{ Year } & \multicolumn{2}{|c|}{ January } & \multicolumn{2}{|c|}{ February } & \multicolumn{2}{|c|}{ November } & \multicolumn{2}{|c|}{ December } \\
\hline & $\begin{array}{c}\text { Number of } \\
\text { days }\end{array}$ & Fog occurred & $\begin{array}{c}\text { Number of } \\
\text { days }\end{array}$ & Fog occurred & $\begin{array}{c}\text { Number of } \\
\text { days }\end{array}$ & Fog occurred & $\begin{array}{c}\text { Number of } \\
\text { days }\end{array}$ & Fog occurred \\
\hline 2002 & 31 & 27 & 29 & 17 & 30 & 29 & 31 & 31 \\
\hline 2003 & 31 & 30 & 28 & 10 & 30 & 2 & 31 & 21 \\
\hline 2004 & 31 & 24 & 28 & 14 & 30 & 10 & 31 & 21 \\
\hline 2005 & 31 & 15 & 28 & 4 & 30 & 5 & 31 & 25 \\
\hline 2006 & 31 & 30 & 28 & 22 & 30 & 15 & 31 & 25 \\
\hline 2007 & 31 & 29 & 28 & 24 & 30 & 30 & 31 & 21 \\
\hline 2008 & 31 & 23 & 29 & 21 & 30 & 25 & 31 & 28 \\
\hline 2009 & 31 & 31 & 28 & 25 & 30 & 18 & 31 & 27 \\
\hline 2010 & 31 & 30 & 28 & 14 & 30 & 21 & 31 & 27 \\
\hline 2011 & 31 & 28 & 28 & 19 & & & & \\
\hline$\%$ & & 79.43 & & 57.3 & & 53.3 & & 78.28 \\
\hline
\end{tabular}

have increased to $71.69 \%$. Table 1 shows that aviation fog occurrence for 4 winter months from 2002-2011 depicts maximum number in January (79.43\%).

This is a significant increase in fog frequencies. The onset of fog over Delhi is associated with the passage of the western disturbances across North West India during winter season [20]. Since the temperature of air near the surface is mostly influenced by the surface itself, the air temperature can easily drop to its dew point on calm, clear nights. Delhi has significant frequencies of low winds, especially during night time. Due to aforementioned site specific local factors, fog forecasting is a complex process and requires adequate representation of the local perturbations in weather prediction models. But its prediction has long been a challenge for operational forecast. This is mainly due to lack of appropriate fog physics in current operational models. It is well known that in operational models cloud schemes are designed for higher level cloud and precipitation instead of fog near the ground. Kunkel [21] has obtained an empirical relation based on LWC (Liquid Water Content) for the visibility estimation that is being applied in many numerical modeling studies for the prediction of fog. Given the fact that the LWC is not accurately resolved by current numerical weather prediction models, this approach however often gives unsatisfactory results. Operational fog forecast is thus generally not directly conducted within a numerical weather prediction model but is diagnosed by a model postprocessor based upon the local atmospheric conditions [22-24]. The main objective of this study is to predict the occurrences and the onset time of fog using the postprocessing of a 3-dimensional mesoscale model. It is multirule based diagnostic (MRD) method which characterizes the local atmospheric conditions. A nonhydrostatic high resolution mesoscale model (WRF version 3.1) is implemented for this purpose along with a fog diagnostic method covering all major fog episodes for the years 2008,
2009, 2010, and 2011 and some nonfoggy days for the sake of comparison.

\section{Study Area and Model Simulation Details}

The study area, New Delhi, is located at latitude $28^{\circ} 53^{\prime}$ and longitude $76^{\circ} 20^{\prime}$ with an altitude of $216 \mathrm{~m}$ above sea level. It is situated on the banks of river Yamuna in the northern part of India. Himalayas are in north of Delhi. The capital of India is a land locked city. The distance from the sea gives Delhi an extreme type of continental climate (http://www.whereincity.com/india/delhi/delhiweather.php). The summers in Delhi are very hot and winters very cold. The temperature range varies from 47 degrees in summers to 3 degrees in winters. The winters are marked by mist and fog in the mornings and often sun is seen in the afternoons. The cold wave from the Himalayan region makes winters very chilly.

The weather research and forecasting (WRF) model is a three-dimensional numerical model. Here we particularly use the Advanced Research WRF model version 3.1.1 for fog simulations. The model features include number of nests, microphysics, cumulus parameterizations, surface physics, $\mathrm{PBL}$, radiation parameterization schemes, and so forth. Since WRF offers a wide range of options for various features, we tested different combinations. Another advantage of this modeling system is that it is a state-of-the-art model. A detailed description of the model is described by Skamarock et al. [25].

The model setup for the present study is comprised of three nested domains with a resolution of 18,6 , and $2 \mathrm{~km}$. Inner domain is centered at Delhi $\left(28.54^{\circ} \mathrm{N}\right.$ and $\left.77.11^{\circ} \mathrm{E}\right)$. Two-way nesting has been done for the two inner domains. Figure 1 shows the entire model domains and nesting. The model used 33 terrains following hydrostatic pressure 


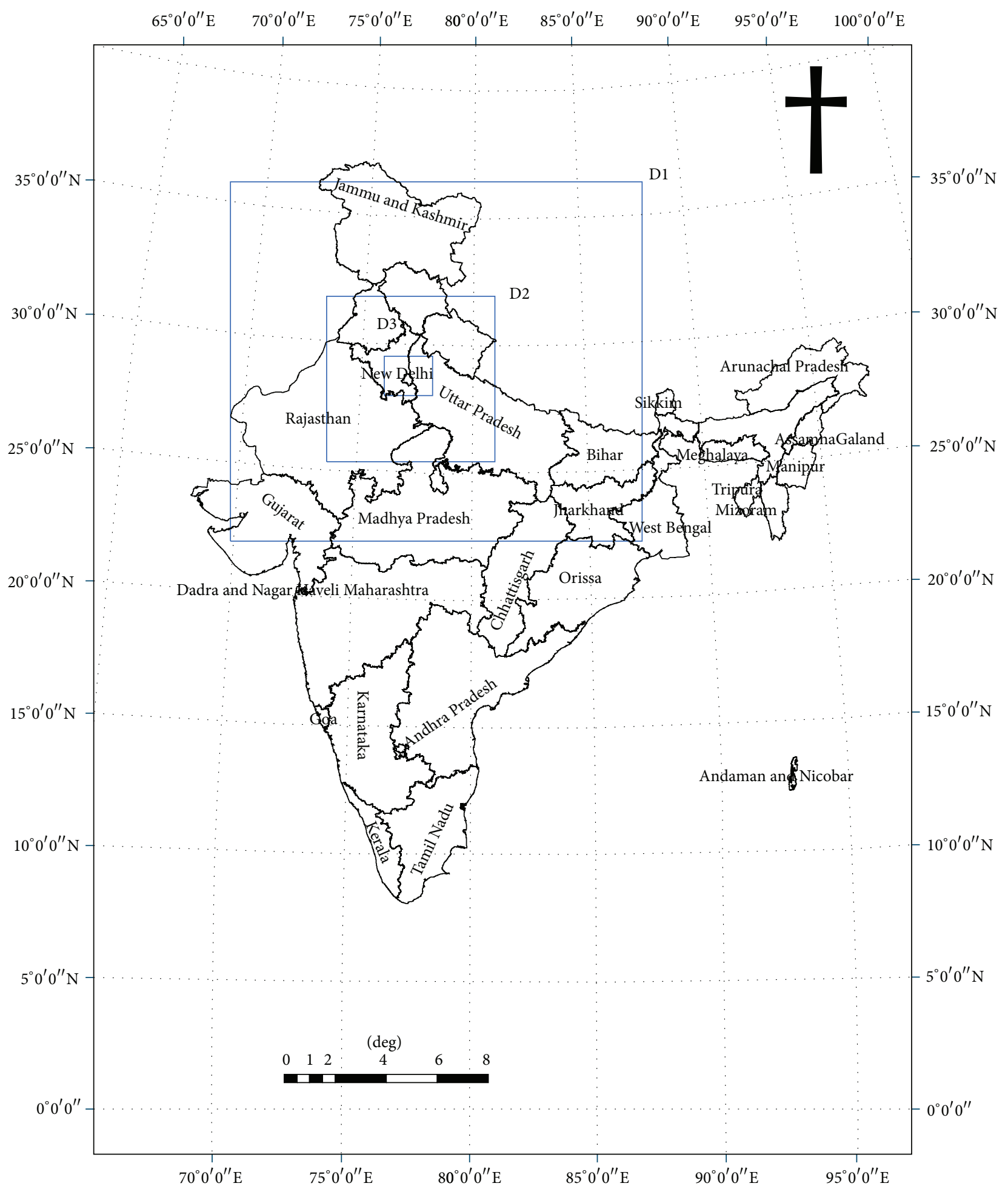

Figure 1

sigma levels from surface $(\sim 970 \mathrm{hPa})$ to $53.5 \mathrm{hPa}$. There are 6 pressure levels available between $\sim 970$ and $\sim 900 \mathrm{hPa}$. NCEP final analysis has been used for initialization. The details of terrain such as vegetation, land-use type, terrain elevation and albedo, and so forth, are made available by two-dimensional terrestrial data provided by the US Geological Survey (USGS).

Sensitivity studies were conducted by [26] with the different combinations of parameterization schemes to determine the optimum configuration of model options over Delhi. 
TABLE 2: Statistical analysis of WRF performance.

\begin{tabular}{lccrr}
\hline & NMSE & Correlation & FB & FAC2 \\
\hline Temperature $\left({ }^{\circ} \mathrm{C}\right)$ & 0.04 & 0.86 & 0.002 & 96.12 \\
Relative humidity $(\%)$ & 0.13 & 0.60 & -0.18 & 90.72 \\
Wind speed $(\mathrm{m} / \mathrm{s})$ & 0.39 & 0.60 & 0.05 & 61.43 \\
\hline
\end{tabular}

This study utilizes the optimum combinations of model options suggested by Mohan and Bhati [26] for the winter season. Accordingly, this study has used Lin et al. [27] for microphysics, Pleim-Xiu for surface layer and land surface, and ACM2 for PBL (Planetary Boundary Layer) and KainFritsch scheme has been chosen for cumulus parameterization. Lin et al. [27] microphysics will have an additional advantage of considering all the hydrometeors. Pleim-Xiu scheme has the advantage of two indirect nudging schemes that correct biases in $2 \mathrm{~m}$ air temperature and $\mathrm{RH}$ by dynamic adjustment of soil moisture and deep soil temperature. These two meteorological parameters are very much important for fog prediction. ACM2 scheme smoothly transits from eddy diffusion in stable conditions to the combined local and nonlocal transport in unstable conditions. This feature is advantageous in the current context as western disturbance is very common in winter over Delhi.

This study is divided in two parts. First part deals with the WRF model validation for the selected fog episodes during the winter period of 2006, 2007, and 2008. Further postprocessing is performed on model outputs for finding appropriate multirule based diagnostic (MRD approach) relationships. The second part is the application of this approach to fog forecasting. The model simulations for the first part are selected from the dense five-fog episodes in the winter period of the years 2006, 2007, and 2008 while the MRD approach is applied for selected five-fog episodes during the winter period of 2008, 2009, 2010, and 2011.

\section{Performance Evaluation of WRF Model}

Simulations have been undertaken for ten different episodes for years 2006 to 2011 consisting of four days each, which are as follows: (i) 2nd to 5th January, 2006, (ii) 1st to 4 th January, 2007, (iii) 25th to 28th January, 2007, (iv) 24th to 27th November, 2007, (v) 4th to 7th January, 2008, (vi) 12th to 15 th January, 2008, (vii) 1st to 4th January, 2009, (viii) 1st to 4 th January, 2010, (ix) 5th to 8th January, 2011, and (x) 18th to 21st November, 2011. Simulations for the first five episodes are used for model performance evaluation and subsequently for postprocessing as per MRD approach to obtain suitable relationships for fog forecasting. These relationships are then applied to forecast fog for the episodes from (vi) to (x) and efficacy of fog forecasting capability is assessed with suitable statistical performance measures.

Meteorological parameters considered for fog predictions in the multirule based diagnostic approach are ambient temperature, relative humidity $(\mathrm{RH})$, and wind speed. Hence these are closely scrutinized for model validation based on the observational data of Palam Airport (Lat $28.6^{\circ} \mathrm{N}$ Lon $77.1^{\circ} \mathrm{E}$ ) in the study area (http://www.wunderground.com/). Model validation is shown here for the first 5 episodes, (i) to (v) totaling twenty days.

The scattered diagram of temperature is shown in Figure 2(a) with FAC2 (predicted values within a factor of two from the observed values) of $96.1 \%$. The correlation between the total simulation days of observed and predicted temperature is 0.86 . The NMSE (Normalized mean square error) for the temperature in all simulated days is 0.04 and fractional bias (FB) is 0.002 . The details of the statistics are shown in Table 2.

The scattered diagram of $\mathrm{RH}$ is shown in Figure 2(b), which shows FAC2 of $90.73 \%$. Correlation coefficient between the total simulation days of observed and predicted relative humidity $(\mathrm{RH})$ is 0.60 . The NMSE value is 0.13 . $\mathrm{RH}$ values are under predicted as shown by the $\mathrm{FB}$ value of 0.18 as also reported by an earlier study [28].

The scattered diagram of wind speed is shown in Figure 2(c). Correlation coefficient and FB for wind speed are 0.60 and 0.05 , respectively, and shows reasonable predictions. NMSE is 0.39 .

Figures 3(a) and 3(b) show, respectively, the observed and simulated wind roses for the entire simulation period. The predominant wind direction for both observed and simulated cases is westerly and depicts satisfactory predictions. Westerly direction is expected over Delhi during fog episodes.

Overall, model performs satisfactorily though there are differences between the observed and simulated values. The differences are systematic so multirule based diagnostic approach (MRD) is developed using predictions of these simulation days. Multirule based diagnostic approach accounts for these differences between observed and predicted values empirically for most of the relevant physical parameters concerning the fog formation. So the first five events including 20 days are used for the development of MRD method. Figures 4(a) and 4(b), 5(a) and 5(b), and 6(a) and 6(b) show the time series of temperature, relative humidity, and wind speed for two events (iv) and (v) of 2007 and 2008. As seen in these figures, temperatures are best simulated followed by $\mathrm{RH}$. However, performance of wind speed simulations is relatively less satisfactory. Physical considerations reveal that temperature and $\mathrm{RH}$ are more important parameters for fog occurrences and onset time while light winds are required to sustain it.

3.1. Multirule Based Diagnostic Methodology. Fog forecasting is in essence the prediction of visibility in foggy conditions. However, the commonly used [21] visibility computation in fog has a very large error (over 50\%) as shown by Gultepe et al. [29]. The unreliable LWC from the operational models causes an even larger visibility computation error. The 


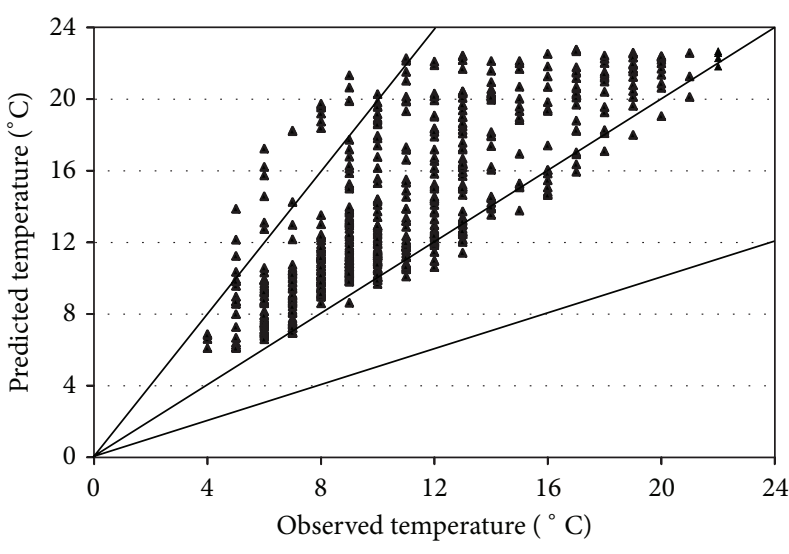

(a)

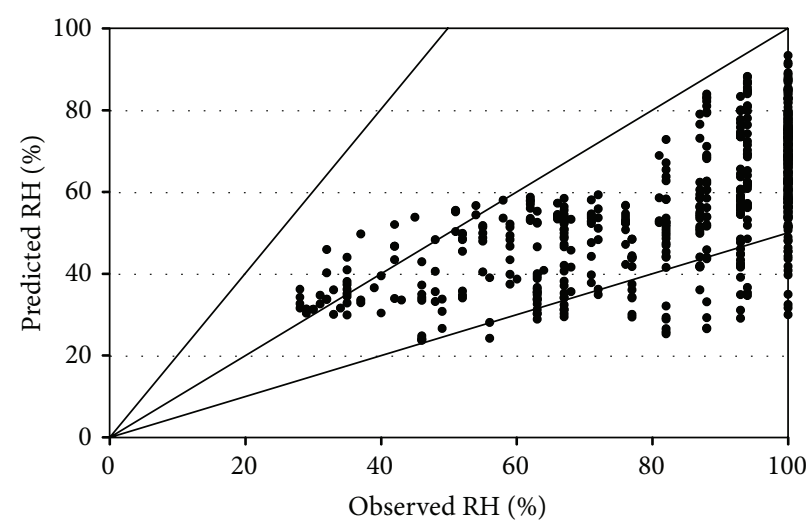

(b)

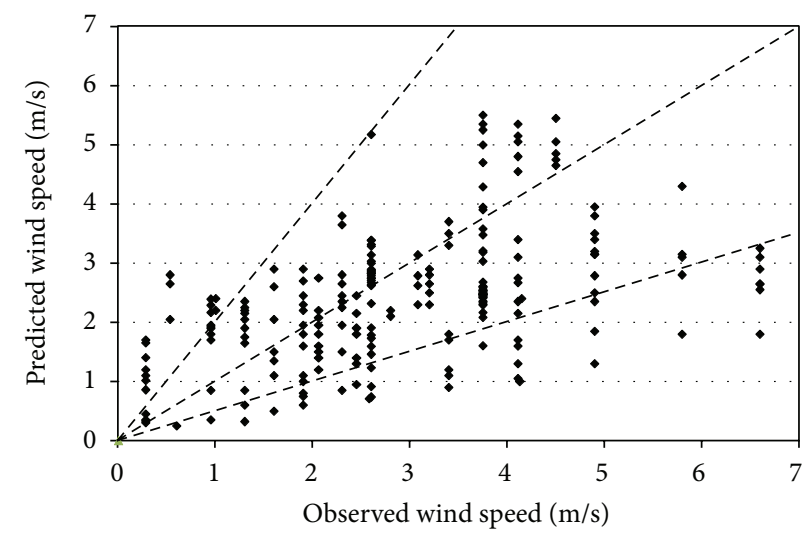

(c)

Figure 2

success rate of the LWC-only approach is particularly low (near zero) for the WRF model in the winter and summer seasons, which demonstrates that the LWC-only method is not reliable [24]. Due to these two facts, only fog occurrence, and not fog intensity (visibility), is diagnosed in the current approach. Focus of this work is to examine the usefulness of a new diagnostic fog forecasting method compared to the conventional LWC [21] method. In a model postprocessor, all the variables are diagnosed under an assumption of steady or quasi-steady condition of the atmosphere. The multivariable based diagnostic fog forecasting includes several parameters to be satisfied as per a given criteria such as temperature, $\mathrm{RH}$, wind speed, and so forth. With a certain threshold criteria for each parameter, the fog occurrence in terms of binary (yes or no) forecast is conducted in a model postprocessor based on the model outputs. Zhou and Du [24] used LWC, cloud base/top rule, and surface RH-wind rule. Cloud base/top rule is good for large scale fog events like marine fog or coastal fog, but not shallow fog or ground fog because this type of fog usually builds upward from the ground and may lie below the lowest model level [30]. Their study also mentioned that $\mathrm{RH}$ at 2 meters should be more than $90 \%$ and wind speed at 10 meters should be less than $2 \mathrm{~m} / \mathrm{s}$ and it worked better when both parameters are considered together than any of the parameters on individual basis. Our multivariable based diagnostic fog forecasting approach is considering the temperature, $\mathrm{RH}$ at surface, and $2 \mathrm{~m}$ levels with wind speeds at 10 meters. To the best of our knowledge, this is first attempt to use meteorological parameter (temperature and $\mathrm{RH}$ ) at two levels for this purpose. A number of factors are responsible for the formation of fog. As is well known, formation of fog is affected to a very large extent by purely local factors. As mentioned above in this section episodes (i) to (v) are used for this purpose. The criteria with regard to each of these variables are described below.

(i) Moisture Associated with Fog Formation. High amount of moisture at the lower level favour the occurrences of fog;

$$
\mathrm{RH}_{\text {Surf }}-\mathrm{RH}_{2}<-4.5 \text {. }
$$

(ii) Surface Wind/Turbulent Mixing. A slight amount of turbulent mixing aids the formation of fog. In the case when the fog is formed much before sunrise, a light surface wind brings about the required mixing;

$$
1.4 \mathrm{~m} / \mathrm{s}<\mathrm{WS}<2.8 \mathrm{~m} / \mathrm{s} \text {. }
$$

(iii) Temperature Gradient Associated with Fogs. Temperature near the ground is another factor contributory to fog 

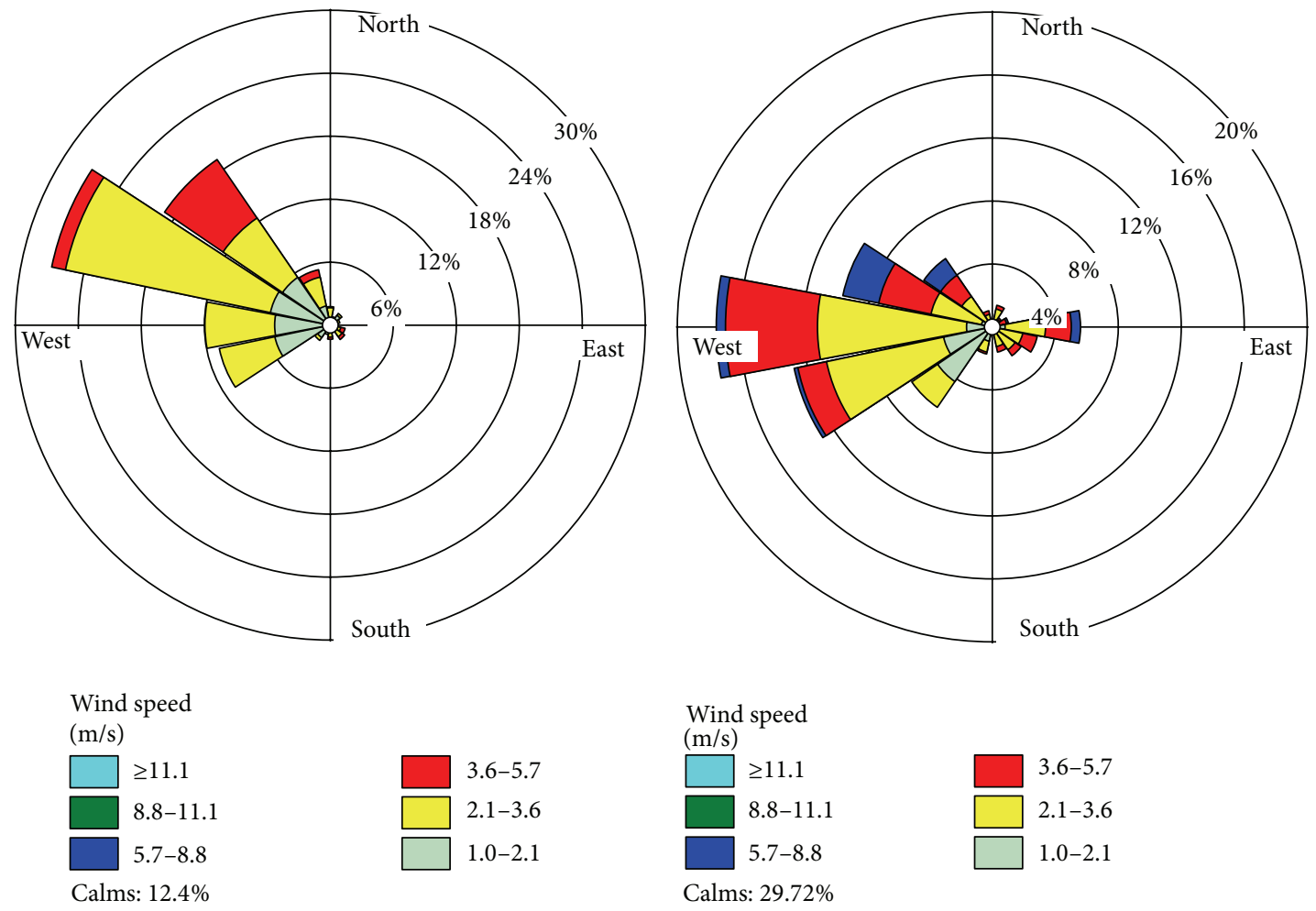

(a)

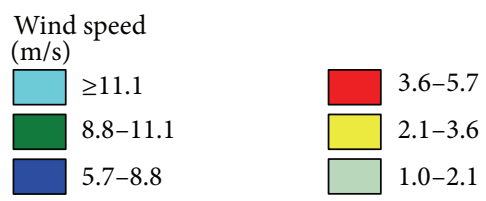

Calms: $29.72 \%$

(b)

Figure 3

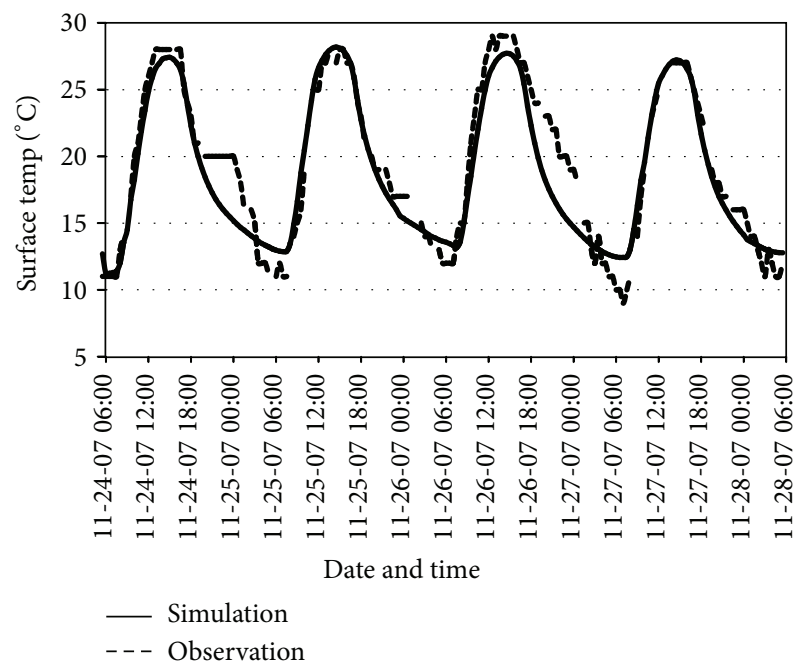

(a)

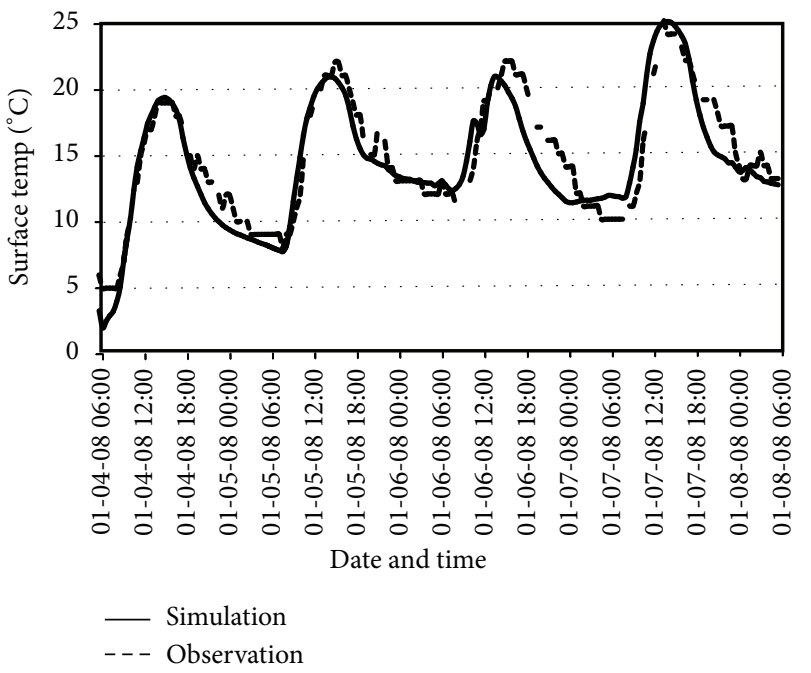

(b)

Figure 4

formation. Depending upon the intensity of near surface temperature gradients, following two criteria are considered in terms of temperature at 2 meters $\left(T_{2}\right)$, surface temperature $\left(T_{\text {Surf }}\right)$, and dew-point depression temperature $\left(T_{\text {Dep }}\right)$ subject to satisfying (1) and (2) above.
Fog occurs in stable condition, so $T_{\text {Surf }}-T_{2}$ should be positive means greater than zero. And the dew-point depression temperature is less than $8^{\circ} \mathrm{C}$.

If air is cooled with respect to its water content, until it becomes saturated, then the temperature at which saturation 


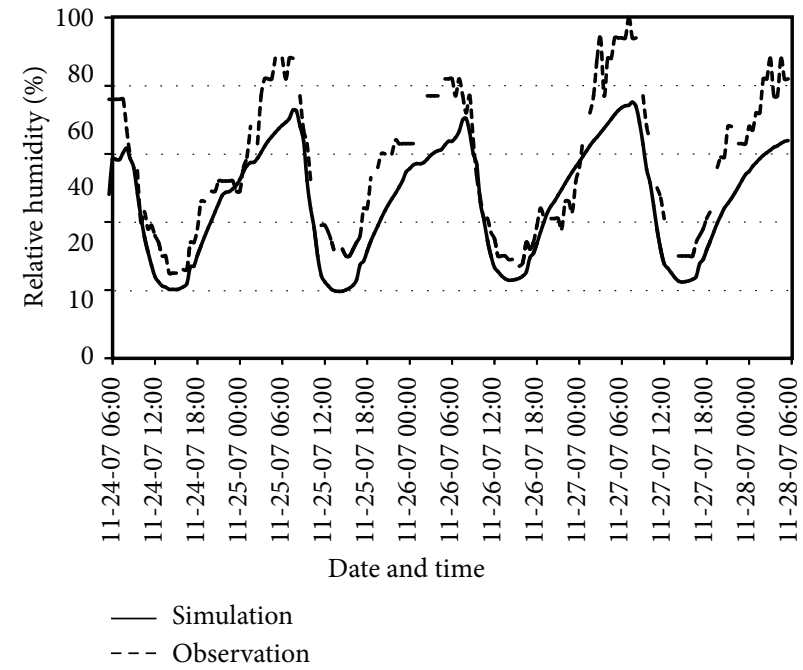

(a)

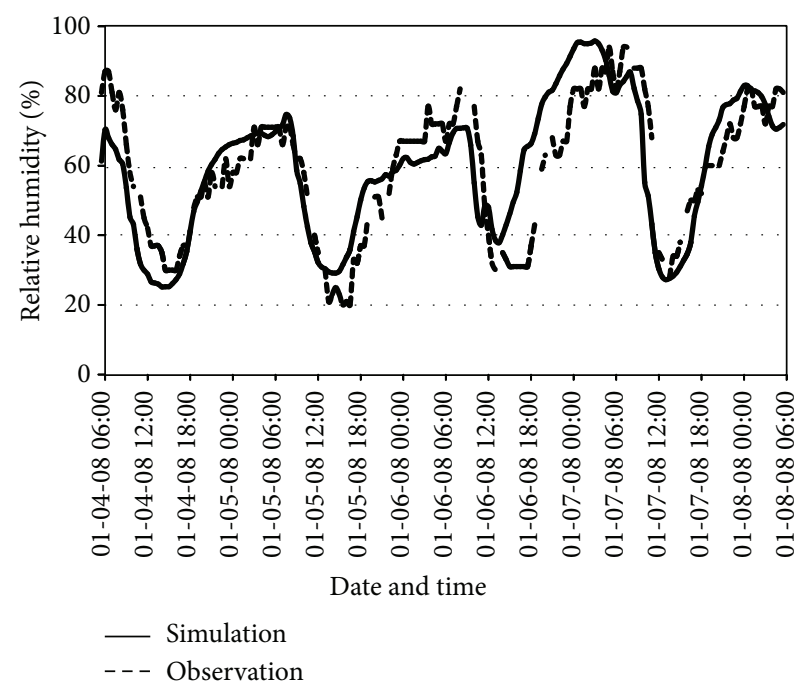

(b)

Figure 5

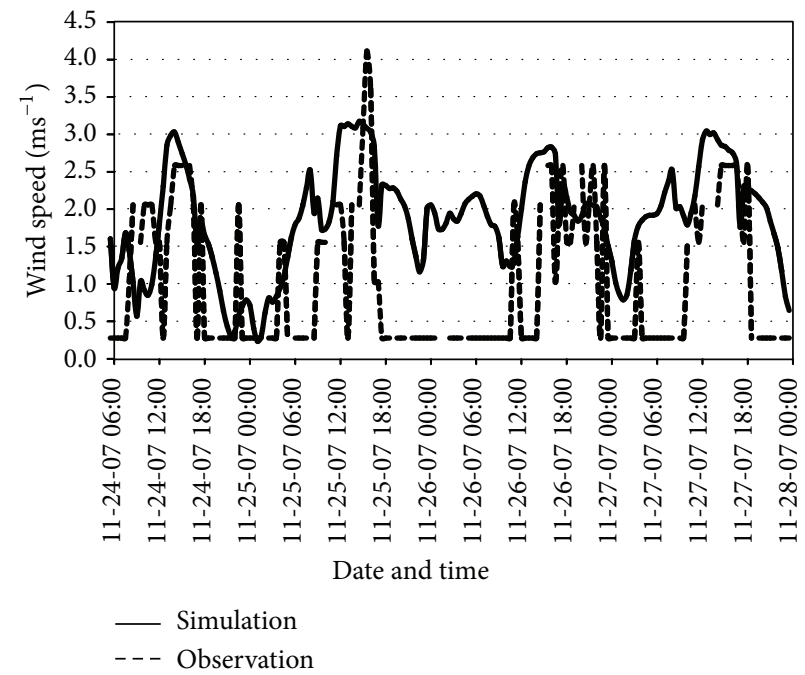

(a)

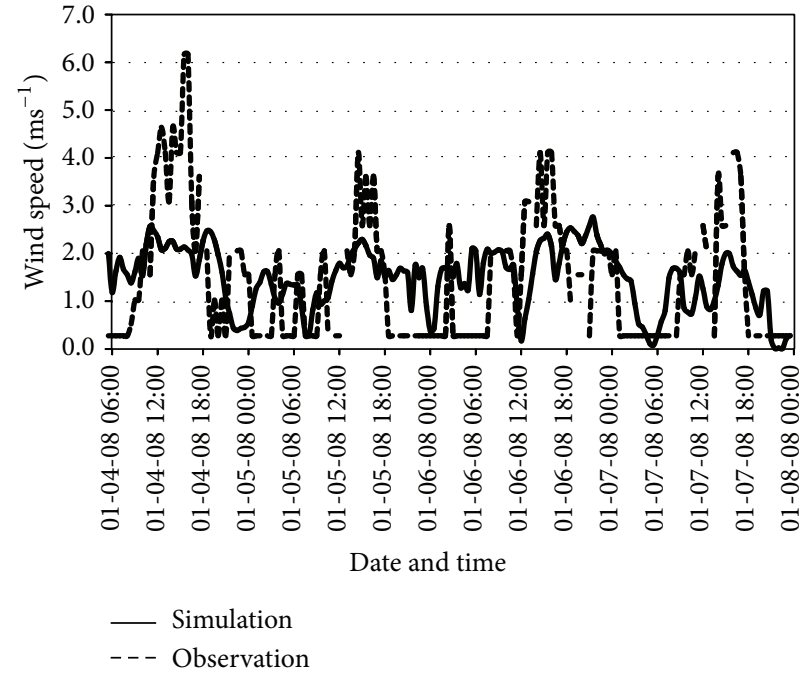

(b)

FIGURE 6

takes place is called the dew-point temperature. Dew-point depression temperature is the difference between dry bulb temperature and dew-point temperature. It shows how close the system is with respect to saturation. Dew-point depression temperature estimated in this study is higher $\left(8^{\circ} \mathrm{C}\right)$ than any of the previous work $\left(6^{\circ} \mathrm{C}\right)[31,32]$. The model simulation catches the signature and trend very well but, due to the systematic under prediction of $\mathrm{RH}$, dew-point temperature is low. As a result dew-point depression temperature becomes higher. The main motive of using postprocessing tool is minimizing this uncertainty. The multirule based diagnosis approach is well fitted in this context.

\section{Fog Events and Synoptic Condition during the Study Period}

Ideal conditions for the formation of fog are light winds, clear skies, and long nights. The months of November, December, January, and February are most prone to foggy conditions. As shown in Table 1, aviation fog occurrence for these 4 months from 2002 to 2011 depicts maximum number in January. Hence the simulations are performed mainly for January months here. Simulations have been performed for five different episodes for years 2008 to 2011 depicted as (vi) to (x) in Section 3 above which are as follows: 12th to 
16th January, 2008; 1st to 4th January, 2009 and 2010; 5th to 8th January, 2011; and 18th to 21st November, 2011. They are classified as Scenarios (SC-\#) and identified as SC-1, SC-2, SC-3, SC-4 and SC-5, respectively. This section describes in detail the observed and synoptic meteorological conditions during each of these scenarios. The results described in this section are taken for these five consecutive simulations unless otherwise stated.

\subsection{SC-1 (12th to 16th January, 2008)}

4.1.1. Observed Surface Meteorological Conditions. The maximum and minimum temperatures were $5^{\circ} \mathrm{C}$ and $22^{\circ} \mathrm{C}$, respectively, and relative humidity varied from $28 \%$ to $100 \%$ during this time. The minimum visibility is 300 meters and maximum is $6 \mathrm{~km}$. 15 January was a nonfoggy day when the maximum relative humidity was $76 \%$. Rest of the days (12-14 and 16) showed more than $92 \% \mathrm{RH}$.

4.1.2. Synoptic Conditions. The study region is influenced by western disturbances as an upper air system developed extending up to $3.6 \mathrm{~km}$ above sea level (a.s.l.) over north Pakistan and adjoining Jammu and Kashmir which later moves east-north-eastwards. The cyclonic circulation over the state of Punjab and neighborhood area persists and extends up to $0.9 \mathrm{~km}$ a.s.l. A cyclonic circulation lies over south Gujarat Region. Cold wave conditions prevail in some parts of west Madhya Pradesh, Rajasthan, and Delhi.

\subsection{SC-2 (1st to 4th January, 2009)}

4.2.1. Observed Surface Meteorological Conditions. 1st to 4th January have maximum foggy hours among all the simulation cases. Visibility ranged from 0.1 to $2.5 \mathrm{~km}$ and highest relative humidity is always $100 \%$ on every day. The minimum relative humidity occurred on the 6 th and the value is $46 \%$. The minimum and maximum temperatures are $5^{\circ} \mathrm{C}$ and $19^{\circ} \mathrm{C}$.

4.2.2. Synoptic Conditions. Cold day conditions are prevailing in some parts of Haryana including Chandigarh, Delhi, and west Uttar Pradesh during the simulation time. The lowest minimum temperature in the plains was $0.9^{\circ} \mathrm{C}$ at Amritsar (Punjab). Western disturbance was weak on first day of simulation but slowly got stronger in due course.

\subsection{SC-3 (1st to 4th January, 2010)}

4.3.1. Observed Surface Meteorological Conditions. Here also the highest relative humidity is $100 \%$ on every day. The minimum visibility touches zero meters. There is a little drizzle on 3 rd October and minimum value of relative humidity reached $82 \%$. The minimum and maximum temperatures are $7^{\circ} \mathrm{C}$ and $21^{\circ} \mathrm{C}$.

4.3.2. Synoptic. The winter season of 2010 experienced many cold waves over the north, central, and peninsular India. Interaction between easterly waves and troughs in midlatitude westerlies gave rise to precipitation over many parts of the country. Fog persisted over the Indo-Gangetic plains on many days during the month of January. During the simulation period, the study region is influenced by western disturbances as a midair system extending up to $1.2 \mathrm{~km}$ above sea level (a.s.l.) over north Pakistan and adjoining Jammu and Kashmir developed which later moved northeast.

\subsection{SC-4 (5th to 8th January, 2011)}

4.4.1. Observed Surface Meteorological Conditions. The minimum temperature $\left(4^{\circ} \mathrm{C}\right)$ and maximum temperature $\left(15^{\circ} \mathrm{C}\right)$ were lowest among all four simulations. The minimum $\mathrm{RH}(63 \%)$ is also highest among all simulations. Highest relative humidity always touches $100 \%$ and the minimum and maximum visibilities are 0 to $2.1 \mathrm{~km}$.

4.4.2. Synoptic Conditions. Delhi experienced many cold waves during this time with strong effect of western disturbance. Fog persisted over the Indo-Gangetic plains with minimum visibility.

\subsection{SC-5 (18th to 21st November, 2011)}

4.5.1. Observed Surface Meteorological Conditions. Delhi experienced fog and it was most dense between 7 and 9 am. Visibility at Safadrjung station was less than 50 meters at 8.30 am. Temperature in northern India, meanwhile, continues to remain higher than normal. The meteorological office attributed this to a western disturbance. November has so far been relatively warm with average temperatures across northwest and central India experiencing 2-3 degrees higher temperature than normal.

4.5.2. Synoptic Conditions. As per the meteorological department, a series of western disturbances affecting northwest India for the past couple of weeks has led to the high temperatures.

\section{Results and Discussion}

Model simulations are evaluated by comparing the modeled results with the observations to examine the quality of simulations, including variations of fog-related parameters (wind profiles, temperature, and relative humidity) during each event. For the purpose of validation, observational data of Palam Airport (Lat $28.6^{\circ} \mathrm{N}$ Lon $77.1^{\circ} \mathrm{E}$ ) is used for comparison with model estimations.

As described in above section, the model has been simulated for Jan-2008 (SC-1), Jan-2009 (SC-2), Jan-2010 (SC-3), Jan-2011 (SC-4), and Nov-2011 (SC-5). Model has been simulated for 4 days for each episode with 48 -hour time slice.

Table 3 lists all the events in detail with fog occurrences (or not) observed and predicted, fog onset time observed and its deviation from the predicted values. For SC-1, the fog onset was observed at 5:00 AM on 15th January, 2008, while model contradicts to predict a "no fog" event. For other days, occurrence or nonoccurrence of fog are predicted 
TABLE 3: Comparison of fog occurrence and observed time.

\begin{tabular}{|c|c|c|c|c|c|c|c|}
\hline \multirow{2}{*}{ Year } & \multirow{2}{*}{ Day } & \multicolumn{3}{|c|}{ Fog occurrences } & \multicolumn{3}{|c|}{ Onset time } \\
\hline & & Observed & Simulated & Comment & Observed & Simulated & Deviation \\
\hline \multirow{4}{*}{2008} & 12th Jan & Fog & Fog & Predicted & $4: 30$ & $4: 00$ & $+30 \mathrm{~min}$ \\
\hline & 13th Jan & Fog & Fog & Predicted & $06: 30$ & 08:00 & $-1 \mathrm{~h} 30 \mathrm{~min}$ \\
\hline & 14th Jan & No fog & No fog & Predicted & - & - & - \\
\hline & 15th Jan & Fog & No fog & Not predicted & 05:00 & - & - \\
\hline \multirow{4}{*}{2009} & 1st January & Fog & Fog & Predicted & 19:00 & 19:00 & 0 \\
\hline & 2nd January & Fog & Fog & Predicted & $21: 00$ & 20:00 & $1 \mathrm{~h}$ \\
\hline & 3rd January & Fog & Fog & Predicted & $18: 00$ & $18: 30$ & $-30 \mathrm{~min}$ \\
\hline & 4th January & Fog & Fog & Predicted & 19:00 & 19:00 & 0 \\
\hline \multirow{4}{*}{2010} & 1st January & Fog & Fog & Predicted & $21: 00$ & $19: 30$ & $+1 \mathrm{~h} 30 \mathrm{~min}$ \\
\hline & 2nd January & Fog & Fog & Predicted & 00:00 & $00: 30$ & $-30 \mathrm{~min}$ \\
\hline & 3rd January & Fog & Fog & Predicted & $23: 00$ & $22: 30$ & $+30 \mathrm{~min}$ \\
\hline & 4th January & Fog & Fog & Predicted & $0: 00$ & 20:00 & $+4 \mathrm{~h}$ \\
\hline \multirow{4}{*}{2011} & 6th January & Fog & Fog & Predicted & $19: 00$ & 19:00 & 0 \\
\hline & 7th January & Fog & Fog & Predicted & $18: 00$ & $18: 30$ & $-30 \mathrm{~min}$ \\
\hline & 8th January & Fog & Fog & Predicted & 18:00 & $18: 30$ & $-30 \mathrm{~min}$ \\
\hline & 9th January & Fog & Fog & Predicted & 18:00 & 19:00 & $-1 \mathrm{~h}$ \\
\hline \multirow{4}{*}{2011} & 18th Nov & Fog & Fog & Predicted & $22: 30$ & $18: 30$ & +4 hours \\
\hline & 19th Nov & Fog & Fog & Predicted & $20: 00$ & $18: 30$ & $+1 \mathrm{~h} 30 \mathrm{~min}$ \\
\hline & 20th Nov & Fog & Fog & Predicted & $18: 00$ & 18.30 & $-30 \mathrm{~min}$ \\
\hline & 21st Nov & Fog & Fog & Predicted & $18: 00$ & $18: 30$ & $-30 \mathrm{~min}$ \\
\hline
\end{tabular}

within 30-90 min. In SC-2, all foggy days are predicted and captured well by the model. The onset of fog is perfectly predicted by model for 1st and 4th January, 2009. But for 2nd and 3rd January, 2009, the model prediction is found to be lagged by 1 hour on 2nd January and half an hour advanced on 3rd January. In case of SC-3, the onset time is usually predicted in advance of actual observed onset time except for 2nd January, 2010. In SC-4, the observed fog onset is in the evening for all the days. The onset of fog on 6th January, 2011 , was predicted perfectly by the model. In SC-5, the onset of fog on 18th November, 2011, was predicted by deviation of 4 hours whereas for 20th and 21st November 2011, model predicted onset at $6: 30 \mathrm{pm}$ but it occurred at $6 \mathrm{pm}$ on both the days. As a conclusion, we see that model is able to capture and reproduce the occurrence or nonoccurrence of fog in 19 out of $20(95 \%)$ events. However the onset time of fog is reproduced $89 \%$ (17 out of 19) within 90 minutes (Table 3 ) which is reasonable. Out of the five episodes spread across twenty days, the diagnostic method successfully predicts 19 out of 20 (95\%) of the foggy and nonfoggy events. This diagnostic approach predicts 16 out of $19(84 \%)$ of onset of fog successfully within 90 minutes. The temporal resolution of the observation and simulation is 30 minutes. More than half $(56 \%)$ of the onset time is predicted within 30 minutes. The only wrong prediction of onset of fog is on 15th January, 2008. There is a scattered cloud. It also happens for 4th January, 2010, and 18th November, 2011, where multirule diagnostic method deviates maximum ( 4 hours). It may be due to the fact that the combination of parameterizations is good for clear sky. This study demonstrates that the combination of WRF and multirule diagnostic method has helped significantly in the improvement of fog predictions and is promising for further application and refinement. However, it only diagnoses the occurrence of fog and its onset time but not the duration and intensity. This calls for further work for completing all aspects of fog prediction. Also its empirical coefficients and criteria can change from place to place and also with different numerical model.

\section{Conclusions}

Primary objective in the present work has been to reproduce the fog occurrences and onset of fog using a dynamical numerical weather prediction model. The method of postprocessing of WRF model output has been used for prediction and onset of fog after successful validation for surface temperature, relative humidity, and wind speed over the region of interest. After analysis of numerous simulations over the study area, criteria for the above meteorological parameters are used to determine the onset of fog. Fog forecasting is achievable by the MRD approach for the next 3 days. The time resolution of the fog forecast is 30 minutes. This skill is realizable in spite of error in mesoscale forecasts because accurate forecast of fog often requires accurate forecasts of (quasi-continues) threshold values of the meteorological fields and MRD approach is able to bridge this gap. With 95\% successful predictions of both foggy and nonfoggy events, more than half $(56 \%)$ of the onset time is predicted within an accuracy of 30 minutes and $84 \%$ of the times it is predicted within 90 minutes. This study demonstrates that the combination of WRF and multirule diagnostic method has 
helped significantly in the improvement of fog predictions. Therefore it is suggested to strengthen this methodology with wider applications at multiple sites and fog episodes.

\section{Conflict of Interests}

The authors declare that there is no conflict of interests regarding the publication of this paper.

\section{Acknowledgments}

This research was partially supported by the Department of Science and Technology (DST), Govt. of India, through a sponsored Research Project on "Fog Prediction Model over Delhi." We also acknowledge the India Meteorological Department for the needful data. This work is a part of Ph.D. thesis of Swagata Payra at IIT Delhi who would also like to thank his colleague Shweta Bhati for her kind assistance.

\section{References}

[1] R. Brown and W. T. Roach, "The physics of radiation fog II-a numerical study," Quarterly Journal of the Royal Meteorological Society, vol. 102, pp. 351-354, 1976.

[2] A. A. M. Holtslag, E. I. F. De Bruijn, and H.-L. Pan, "A high resolution air mass transformation model for short-range weather forecasting," Monthly Weather Review, vol. 118, no. 8, pp. 1561-1575, 1990.

[3] T. Bergot and D. Guedalia, "Numerical forecasting of radiation fog. Part I. Numerical model and sensitivity tests," Monthly Weather Review, vol. 122, no. 6, pp. 1218-1230, 1994.

[4] R. A. Capon, "Development of very high resolution models for fog prediction," Geophysical Research Abstracts, vol. 7, Article ID 08040, 2005.

[5] J. Fišák, D. Řezáčová, and J. Mattanen, "Calculated and measured values of liquid water content in clean and polluted environments," Studia Geophysica et Geodaetica, vol. 50, no. 1, pp. 121-130, 2006.

[6] T. Bergot, E. Terradellas, J. Cuxart et al., "Intercomparison of single-column numerical models for the prediction of radiation fog," Journal of Applied Meteorology and Climatology, vol. 46, no. 4, pp. 504-521, 2007.

[7] M. Mohan and S. K. Nigam, "Modelling techniques for fog prediction model and review," Indian Journal of Environmental Protection, vol. 23, no. 5, pp. 481-488, 2003.

[8] S. P. Ballard, B. W. Golding, and R. N. B. Smith, "Mesoscale model experimental forecasts of the Haar of northeast Scotland," Monthly Weather Review, vol. 119, no. 9, pp. 2107-2123, 1991.

[9] M. Pagowski, I. Gultepe, and P. King, "Analysis and modeling of an extremely dense fog event in southern Ontario," Journal of Applied Meteorology, vol. 43, no. 1, pp. 3-16, 2004.

[10] G. Fu, J. Guo, S.-P. Xie, Y. Duan, and M. Zhang, "Analysis and high-resolution modeling of a dense sea fog event over the Yellow Sea," Atmospheric Research, vol. 81, no. 4, pp. 293-303, 2006.

[11] M. Nakanishi and H. Niino, "An improved Mellor-Yamada Level-3 model: its numerical stability and application to a regional prediction of advection fog," Boundary-Layer Meteorology, vol. 119, no. 2, pp. 397-407, 2006.
[12] I. R. van der Velde, G. J. Steeneveld, B. G. J. Wichers Schreur, and A. A. M. Holtslag, "Modeling and forecasting the onset and duration of severe radiation fog under frost conditions," Monthly Weather Review, vol. 138, no. 11, pp. 4237-4253, 2010.

[13] G. V. Rao and J. O'Sullivan, "A review of some recent radiation fog prediction studies and the results of integrating a simple numerical model to predict radiation fog over Brunei," in Air Quality, Pageoph Topical Volumes, pp. 239-250, Birkhäuser, Basel, Switzerland, 2003.

[14] W. D. Meyer and G. V. Rao, "Radiation fog prediction using a simple numerical model," Pure and Applied Geophysics, vol. 155, no. 1, pp. 57-80, 1999.

[15] R. K. Gupta, "On the technique of forecasting fog/stratus over the dundigal airfield of hydrabad," Mausam, vol. 38, no. 4, pp. 401-406, 1987.

[16] M. Mohapatra and A. Thulsidas, "Analysis and forecasting of fog over Bangalore airport," Mausam, vol. 49, no. 1, pp. 135-142, 1998.

[17] S. K. Roybhowmik, A. M. Sud, and C. Singh, "Forecasting fog over Delhi-anobjective method," Mausam, vol. 55, no. 2, pp. 313-322, 2004.

[18] P. Goswami and A. Tyagi, "Advance forecasting of onset, duration and hourly fog intensity over Delhi," Research Report RR CM 0714, Centre for Mathematical Modelling and Computer Simulation, Bangalore, India, 2007.

[19] M. Mohan and S. Payra, "Influence of aerosol spectrum and air pollutants on fog formation in urban environment of megacity Delhi, India," Environmental Monitoring and Assessment, vol. 151, no. 1-4, pp. 265-277, 2009.

[20] K. Kundu T, "Fog over Safdarjung airfield," Journal of Meteorology \& Geophysics, vol. 4, pp. 296-302, 1957.

[21] B. A. Kunkel, "Parameterization of droplet terminal velocity and extinction coefficient in fog models," Journal of Climate and Applied Meteorology, vol. 23, no. 1, pp. 34-41, 1984.

[22] D. F. Leipper, "Fog forecasting objectively in the California coastal area using LIBS," Weather and Forecasting, vol. 10, no. 4, pp. 741-762, 1995.

[23] B. Zhou and B. S. Ferrier, "Asymptotic analysis of equilibrium in radiation fog," Journal of Applied Meteorology and Climatology, vol. 47, no. 6, pp. 1704-1722, 2008.

[24] B. Zhou and J. Du, "Fog prediction from a multimodel mesoscale ensemble prediction system," Weather and Forecasting, vol. 25, no. 1, pp. 303-322, 2010.

[25] W. C. Skamarock, J. B. Klemp, J. Dudhia et al., "A description of the advanced research WRF version 3," NCAR Technical Note NCAR/TN-475+STR, 2008.

[26] M. Mohan and S. Bhati, "Analysis of WRF model performance over subtropical region of Delhi, India," Advances in Meteorology, vol. 2011, Article ID 621235, 13 pages, 2011.

[27] Y.-L. Lin, R. D. Farley, and H. D. Orville, "Bulk parameterization of the snow field in a cloud model," Journal of Climate and Applied Meteorology, vol. 22, no. 6, pp. 1065-1092, 1983.

[28] E. Flaounas, S. Bastin, and S. Janicot, "Regional climate modelling of the 2006 West African monsoon: sensitivity to convection and planetary boundary layer parameterisation using WRF," Climate Dynamics, pp. 1-23, 2010.

[29] I. Gultepe, G. Pearson, J. A. Milbrandt et al., "The fog remote sensing and modeling field project," Bulletin of the American Meteorological Society, vol. 90, no. 3, pp. 341-359, 2009.

[30] B. Zhou, J. Du, B. S. Ferrier, J. McQueen, and G. DiMego, "Numerical forecast of fog-central solutions," in Proceedings 
of the 2nd Conference on Weather Analysis and Forecasting and 18th Conference on Numerical Weather Prediction, American Meteorological Society, Park City, Utah, USA, June 2007, http://ams.confex.com/ams/pdfpapers/123669.pdf.

[31] T. M. Seidel, A. N. Grant, A. A. P. Pszenny, and D. J. Allman, "Dewpoint and humidity measurements and trends at the summit of Mount Washington, New Hampshire, 1935-2004," Journal of Climate, vol. 20, no. 22, pp. 5629-5641, 2007.

[32] P. J. Croft, R. L. Pfost, J. M. Medlin, and G. A. Johnson, "Fog forecasting for the southern region: a conceptual model approach," Weather and Forecasting, vol. 12, no. 3, pp. 545-556, 1997. 

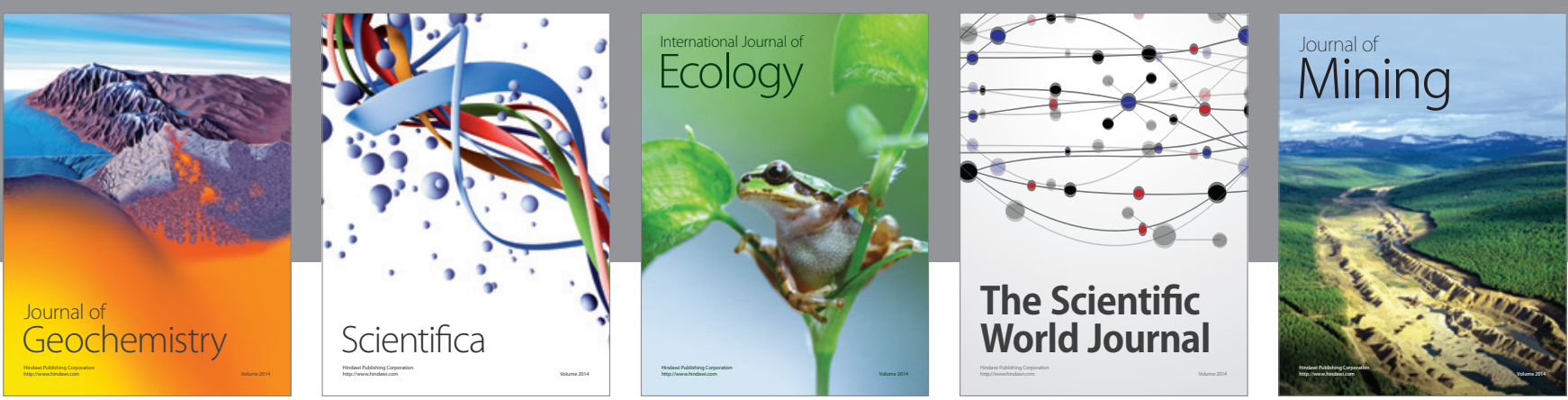

The Scientific World Journal
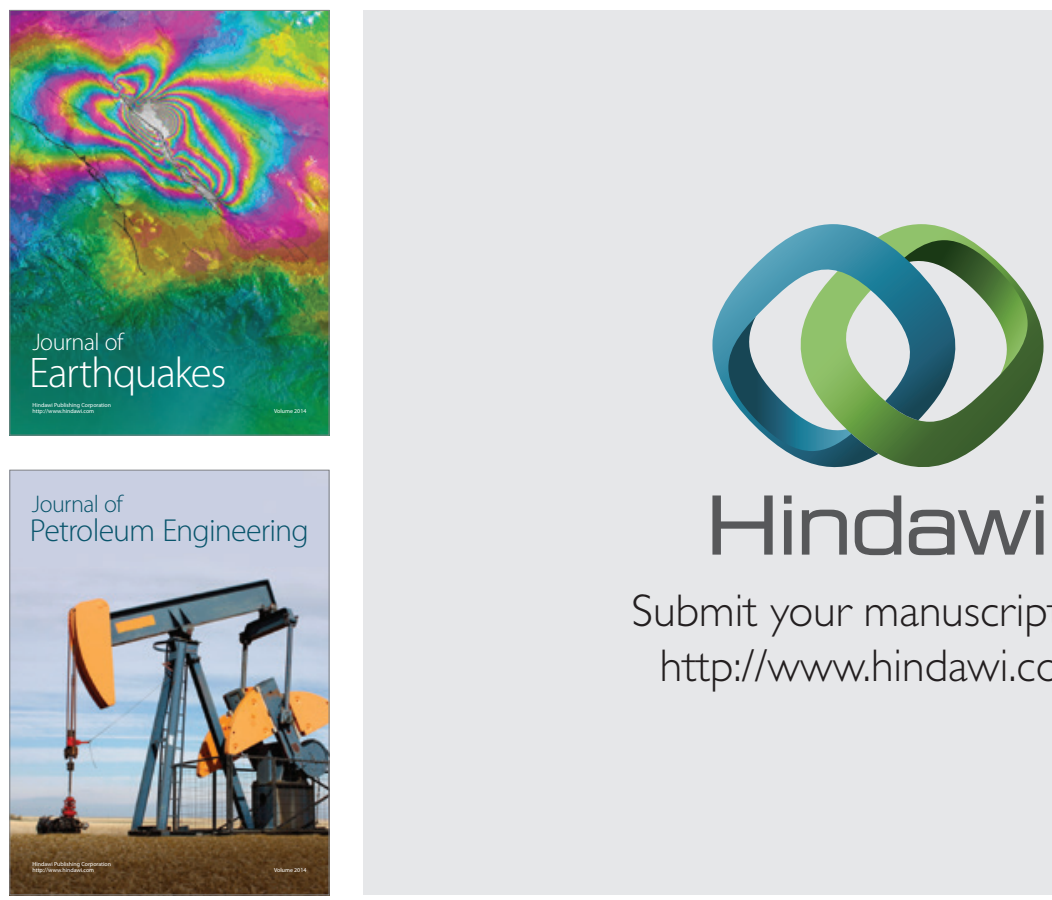

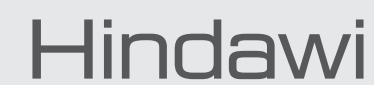

Submit your manuscripts at

http://www.hindawi.com
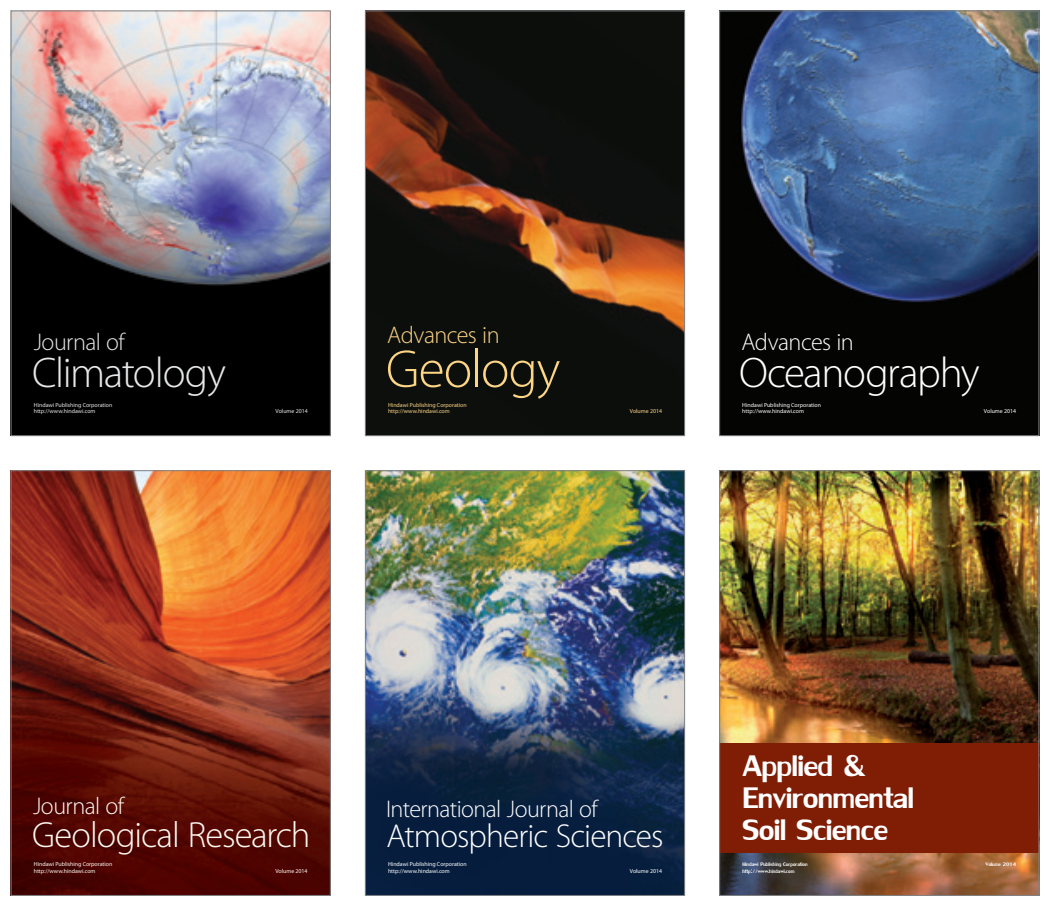
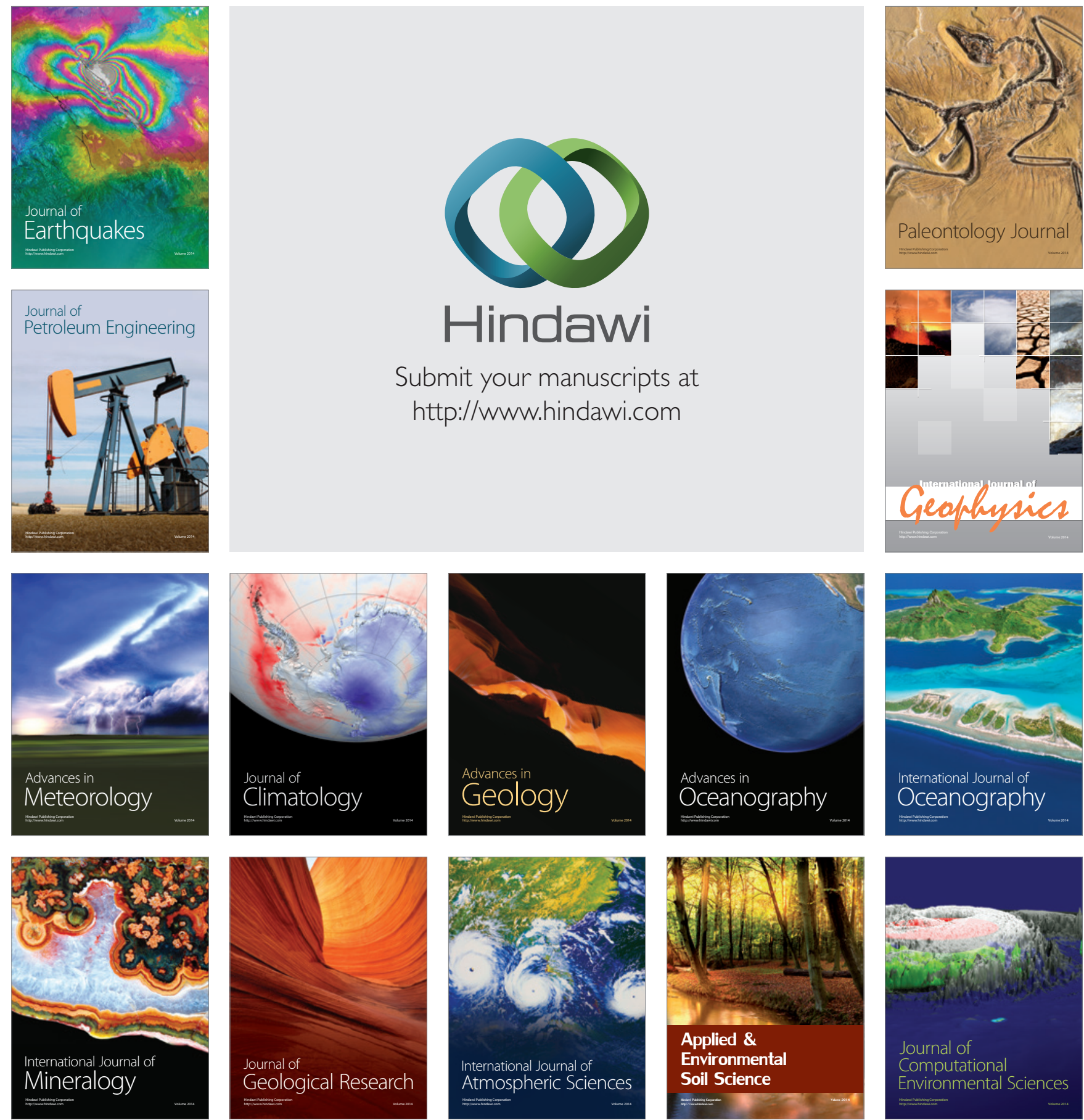